\title{
Evaluation of different oral care systems: Results for Germany and selected highly developed countries. An update of a former study
}

\author{
Ruediger Saekel* \\ Formerly Head of Department of "Dental Provision“ in the Federal Ministry of Health, Bonn, Germany
}

\begin{abstract}
Objective: Evaluation of different types of oral care systems by means of new analytical tools that facilitate the obtention of quantifiable results.

Methods: Construction of an expanded composite indicator that measures dental health on a population basis in the form of one overall indicator - the Dental Health Index (DHI). If the DHI is combined with a Dental Care Cost Index (DCCI), an efficiency index can be created. The study uses additional contemporary outcome data.

Results: The Swedish population enjoys by far the best dental health status. Successive ranks are occupied by Denmark, Germany, Canada, the United Kingdom, the USA and Japan, whereby the DHIs for these countries differ only slightly. The Dutch and Finnish populations enjoy a lesser degree of dental health. Advanced oral health can be achieved in any oral healthcare system, irrespective of the funding structures. However, the design of an oral health system matters, when it comes to patient satisfaction. On the basis of this criteria, European insurance-based systems perform better. The type of care system also matters, when efficiency considerations come into play. In these instances, national health systems seem to perform better.

Conclusion: Across systems, the comparison shows that systems strengthening preventive and tooth-preserving strategies, inclusive of adults, progress faster and perform better in respect of effectiveness and efficiency. A macroeconomic cost level of between $0.5 \%$ and $0.7 \%$ of GDP can be regarded as a benchmark for an efficient dental care system in affluent societies.
\end{abstract}

\section{Introduction}

There are numerous cross-national studies that focus on partial aspects of dental status or on certain characteristics of the dental system. However, the results of all of these studies are only valid for the analysed subgroups or objects of investigation and may not be generalised for the whole population or the entire dental care system [1-5]. For, in the past, countries with low caries prevalence in children and adolescents showed high rates of missing teeth already in middle-aged adults paired with extraordinarily high rates of edentulism in seniors (age-bracket 65/74) [6,7]. This means that caries experience does not develop steadily over a lifetime. As a result, a single indicator that corresponds to a certain age-bracket is unable to depict the oral health status of the whole population.

One of the rare residual international comparisons with a genuine population perspective is the work of Crocombe, et al. [8], which uses different single indicators for a few age-brackets. However, as their results are contradictory in sub-areas, it is difficult to draw clear, final conclusions.

That is why the present study uses a newly developed overall indicator for measuring the oral health status from a population perspective. This 'Dental Health Index' (DHI) of a nation's population, created by Bauer, et al. [9], has proven itself in several studies [10,11] and is used here as a basis.

In addition to measuring a DHI, a cost index for recording the macroeconomic resource consumption by the dental sector is created
(Dental Care Cost Index, DCCI), in order to conduct a benefit/cost analysis of the entire dental care system. This investigation is an update of a former study [12] as important new representative epidemiological studies have become available in the meantime. To ensure that this updated article can be read and understood on its own, a few repetitions of the former text are inevitable.

\section{Material and methods}

As dental decay and its implications (tooth loss) account for about $95 \%$ of the oral disease burden across the world [13], the DHI focuses on dental decay and its consequences. By doing so, severe periodontal diseases are indirectly included in the oral health status measurement, which is helpful as they may also cause tooth loss at a more advanced age. The DHI is composed of several single indicators for the corresponding WHO standard reference age classes and additionally includes - in contrast to the former study [12] - the indicator 'missing teeth (MT)' in seniors. The MT value measures the cumulated oral damage during the course of life and thus enables conclusions on a

Correspondence to: Formerly Head of Department of "Dental Provision" in the Federal Ministry of Health, Bonn, Germany, E-mail: ruediger@saekel.de; Home page: www.saekel.com

Key words: benefit/cost analysis of the dental sector, overall dental health indicator, performance of dental care sytems, efficiency of a country's oral care

Received: April 09, 2018; Accepted: April 27, 2018; Published: April 30, 2018 
dental care system's effectiveness in achieving the priority aim of the "retention of natural teeth until an advanced age [11]. By including this meaningful cumulative single value in the composite DHI indicator, countries that achieve more elevated rates of retained teeth at senior age are ranked better than others, which seems justified. As a result, the explanatory power of the DHI improves substantially.

Expressed as a formula, the enlarged DHI reads like this:

DHI $=($ Caries-free Index 5/6 + DMFT $12+$ DMFT 35/44 + MT Index 65/74 + Edentulism Index 65/74): 5

The lower the DHI, the better the population's oral health status. The detailed construction of the DHI is described elsewhere $[11,12]$. The link between the DHI and the DCCI, defined as a proportion of total oral healthcare costs in relation to Gross Domestic Product (GDP), gives rise to the Efficiency Index (EI). To ensure that both indices indicate improvements in the same manner and direction, the practical link is achieved by adding the two indices together. Thus, better dental health in a country's population, as well as diminishing macroeconomic resources for oral health care, are indicated by decreasing indices. In mathematical terms, the formula reads:

Efficiency Index $(E I)=$ Dental Health Index $(D H I)+$ Dental Care Cost Index (DCCI)

In other words, the lower the efficiency value, the better the benefit/ cost ratio within the dental care sector.

The new overall indicators for measuring the benefit and cost of an oral care system are applied, in this study, to highly developed countries with different types of health care systems, whose young generations display remarkable level of oral health. These include Social Security models (Germany, France, the Netherlands, Japan), National Health Service models (United Kingdom, Sweden, Denmark, Finland), Private Insurance models (USA, Switzerland, Canada), and mixed private/ public models (Australia). Switzerland and Canada, which have a social security system, in principle, are assigned here to the private insurance model as the health legislator in both countries explicitly chose not to include dental care in the healthcare system (except when it relates to children, expectant mothers and public assistance recipients) [14].

As was the case with the preceding study [12], the present study is also a descriptive and cross-sectional investigation, based on existing data. It also includes additional longitudinal findings from regular surveys and furnishes evidence of relationships and influencing factors. Conclusions on cause and effect are limited.

\section{Results}

With a DHI of 3.18, the Swedish population enjoys by far the best oral health status (Table 1). With DHIs of 4.42, 4.53, 4.64 as well as 4.66 and 4.72 Denmark, Germany, Canada, the United Kingdom, USA, and Japan, respectively, occupy ranks two to seven with almost the same results. In the latter six countries, the population's oral health status is roughly $40 \%$ to $50 \%$ lower than in Sweden.

After a substantial gap, France, Australia and Switzerland occupy the following ranks, leaving the last two places to Finland and the Netherlands, with DHIs of 6.48 and 6.60. However, it must be said that the oral health data for middle-aged adults in both countries are relatively old. A current Finnish study, for example, reveals that the oral health status of middle-aged adults improved between 2000 and 2011[15].

There is a difference of more than $100 \%$ in terms of oral health status between the first and the twelfth rank. This means that Swedish people enjoy a level of oral health that is twice as good as that of the Dutch population. Considering the results of the single indicators for the corresponding age-brackets, it is noticeable that great differences in oral health begin only in adulthood (Table 1).

As a complement to the cross-sectional data, Table 2 shows available longitudinal data on the development of the dentition of adults and seniors from several of the countries studied. Especially distinct are the reductions in edentulism in older Swedish, Danish, Japanese and Swiss people. The fact that, in the United Kingdom, caries decline extends to all age brackets proves the degree to which the preventive and tooth preserving approach practised by British dentists is widespread, even among adults [26]. In Germany, it is noticeable that improvements in the oral health status of adults start later and are less distinct than in other countries. All in all, the longitudinal survey data, arranged according to the decrease in edentulous seniors, tend to support the ranking established using DHI.

A general evaluation of the oral health status in the various age brackets shows that further progress in all countries can be expected, if present trends remain stable. Only Denmark and Sweden, with around $80 \%$ of caries-free deciduous teeth have exploited their potential to

Table 1. Dental Health Index of the population (DHI) in selected highly developed countries for the period 2006-2014

\begin{tabular}{|c|c|c|c|c|c|c|c|c|c|c|c|}
\hline \multirow{2}{*}{ Country } & \multirow{2}{*}{ Survey year } & \multicolumn{2}{|c|}{$\begin{array}{c}\text { Caries-free } \\
5 / 6\end{array}$} & \multirow{2}{*}{$\begin{array}{c}\text { DMF-T } \\
12 \\
(2)\end{array}$} & \multirow{2}{*}{$\begin{array}{c}\text { DMF-T } \\
35 / 44 \\
(3)\end{array}$} & \multicolumn{2}{|c|}{$\begin{array}{l}M^{M}-T^{2} \\
65 / 74\end{array}$} & \multicolumn{2}{|c|}{ Edentulism 65/74 } & \multirow{2}{*}{$\begin{array}{c}\text { DHI }^{10} \\
(6)\end{array}$} & \multirow{2}{*}{ Rank } \\
\hline & & in $\%$ & Index (1) & & & abs. & Index (4) & in \% & Index (5) & & \\
\hline SE & $2011 / 13$ & 79 & 2,1 & 0,8 & $9,7^{5}$ & 4 & 3 & 2,7 & 0,3 & 3,18 & 1 \\
\hline DK & $2009 / 14$ & 75 & 2,5 & 0,4 & 13,5 & 8 & 5 & 6,8 & 0,7 & 4,42 & 2 \\
\hline $\mathrm{DE}$ & $2014 / 16$ & $>62$ & 3.8 & 0.44 & 11,2 & 11,1 & 6 & 12,4 & 1,2 & 4.53 & 3 \\
\hline $\mathrm{CA}$ & $2007 / 9$ & 53 & 4,7 & 1,0 & $12,3^{8}$ & $5,6^{9}$ & 3 & 21,7 & 2,2 & 4,64 & 4 \\
\hline $\mathrm{UK}^{1}$ & $2009 / 13$ & $<69$ & 3,1 & 0.8 & 11,9 & 11,1 & 6 & 15,0 & 1,5 & 4,66 & 5 \\
\hline US & $2004 / 10$ & 53 & 4,7 & 1,19 & 10,91 & 8,3 & 5 & 15,0 & 1,5 & 4,66 & 6 \\
\hline JP & 2011 & 58 & 4,2 & 1,4 & 12,3 & 9,1 & 5 & 6,9 & 0,7 & 4,72 & 7 \\
\hline FR & $1994 / 06 / 13$ & 63 & 3,7 & 1,23 & $14,6^{3}$ & 9 & 5 & 9,1 & 0,9 & 5,09 & 8 \\
\hline $\mathrm{AU}$ & $2005 / 09 / 10$ & 49 & 5,1 & 1,05 & 10,7 & 12 & 7 & $21,1^{7}$ & 2,1 & 5,19 & 9 \\
\hline $\mathrm{CH}$ & $2002 / 11 / 13$ & 51 & 4,9 & 0,9 & $14,5^{4}$ & 8 & 5 & 6,7 & 0,7 & 5,20 & 10 \\
\hline FI & $2001 / 09$ & 39 & 6,1 & 0,7 & 16,0 & 11,7 & 6 & 36,0 & 3,6 & 6,48 & 11 \\
\hline NL & $1998 / 09 / 13$ & $60^{5}$ & 4,0 & $0,8^{6}$ & 17,4 & 14 & 8 & 27,6 & 2,8 & 6,60 & 12 \\
\hline
\end{tabular}

1) Without Scotland; 2) Basis: 28 teeth; 3) Rhone/Alps; 4) Canton Zürich; 5) Jönköping; 6) Den Haag; 7) 65+; 8) 40-59; 9) 60-79; 10) DHI (6)=[(1)+(2)+(3)+(4)+(5)]: 5 [16-25] 
Table 2. Changes in the dental status of adults in a selection of highly developed countries for the period 1972-2014

\begin{tabular}{|c|c|c|c|c|c|c|c|}
\hline \multirow{2}{*}{$\begin{array}{c}\text { Age class } \\
65 / 74\end{array}$} & \multirow{2}{*}{$\begin{array}{c}\text { Country } \\
\text { SE }\end{array}$} & \multirow{2}{*}{$\begin{array}{c}\text { Period } \\
1980-2013\end{array}$} & \multirow{2}{*}{$\begin{array}{l}\text { Indicator } \\
\text { Edentulism }\end{array}$} & \multicolumn{3}{|c|}{ Results in \% } & \multirow{2}{*}{$\begin{array}{c}\Delta \text { in \% } \\
-94\end{array}$} \\
\hline & & & & 44.2 & $\nabla$ & 2.7 & \\
\hline $35+$ & \multirow{3}{*}{ DK } & $1975-2005$ & Edentulism & 36.4 & $\nabla$ & 5.0 & -86 \\
\hline $65 / 74$ & & $1987-2008 / 9$ & Edentulism & 51.0 & $\nabla$ & 6.8 & -87 \\
\hline $65 / 74$ & & $1987-2000$ & Functional dentition $^{2}$ & 16.0 & 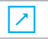 & 40.0 & 150 \\
\hline $20-65+$ & \multirow{3}{*}{$\mathrm{UK}^{1}$} & $1978-2009$ & Edentulism & 28.0 & $\nabla$ & 6.0 & -79 \\
\hline $65 / 74$ & & & Edentulism & 78.0 & $\nabla$ & 15.0 & -81 \\
\hline $20-65+$ & & & Prevalence of dental decay & 46.0 & $\nabla$ & 28.0 & -39 \\
\hline $65 / 74$ & \multirow{2}{*}{ JP } & $1987-2011$ & Functional dentition & 22.0 & 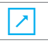 & 60.0 & 173 \\
\hline $65 / 74$ & & & Edentulism & 30.0 & $\nabla$ & 6.9 & -77 \\
\hline $65 / 74$ & \multirow{2}{*}{$\mathrm{CH}$} & $1992-2002$ & Missing Teeth (MT) & 15.4 & $\nabla$ & 10.4 & -33 \\
\hline $65 / 74$ & & $1992-2013$ & Edentulism & 26.8 & $\nabla$ & 6.7 & -75 \\
\hline $65 / 74$ & $\mathrm{DE}$ & $1997-2014$ & Functional dentition & 22.0 & $\nearrow$ & 53.4 & 142 \\
\hline $65 / 74$ & & & Edentulism & 24.8 & $\nabla$ & 12.4 & -50 \\
\hline $20-79$ & $\mathrm{CA}$ & $1972-2010$ & Edentulism & 23.6 & $\nabla$ & 6.4 & -73 \\
\hline $30-75+$ & FI & $1980-2000$ & Edentulism & 29.5 & $\nabla$ & 14.5 & -51 \\
\hline
\end{tabular}

1) Without Scotland; 2) $\geq 20$ retained teeth (FDWHO-Model) [17,18-22,27-29]

the fullest. In French and Japanese adolescents, minor progress can be expected, whereas all other countries already fall into the WHO category with "very low caries" (DMFT < 1.2). Most reserves exist in the adult population. Among middle-aged adults, only Sweden, Australia, the USA, Germany, the United Kingdom, Japan and Canada reveal a "low caries burden" (DMFT 5.0-13.9). Significantly more room for improvement exists in the remaining countries. How realistic this is can be observed in the highly developed Asian countries/regions (South Korea, Singapore, Hong Kong and Taiwan) where this age-bracket is able to achieve DMFT values between 5.5 and 7.4 [11].

A look at the MT values of seniors is particularly enlightening from two perspectives: Firstly, from a methodological perspective, the trend exhibited by the MT values in the countries under study correlates well with the composite indicator DHI, indicating that the DHI reliably reflects a nation's oral health status (Figure 1).

Secondly, the MT value allows us to generate the number of retained natural teeth of a country's population, which is meaningful for public health policy as it indicates how successful health policy was in achieving the goal of "tooth retention until advanced age". Figure 2 shows the results of such a process. According to the results, Sweden and Canada achieved the highest tooth retention levels, with 24 and 22.4 retained teeth, respectively, in $65 / 74$ year olds. With on an average of 20 to 18.9 remaining natural teeth, the level of tooth retention among Danish, Swiss, US-American, French and Japanese seniors is less distinct, but still higher than in Germany, the United Kingdom, Finland and Australia. With 14 retained natural teeth, Dutch seniors exhibit the lowest grade of tooth retention meaning that, on average, they have lost half of their dentition.

Even more disparate are the values for edentulism in seniors (Table 1). While the Swedish, Swiss, Danish and Japanese populations enjoy a low prevalence of edentulism among the elderly $(2.7 \%, 6.7 \%$, $6.8 \%$ and $6.9 \%$ respectively), the rates in Germany, the USA and the United Kingdom are moderate (12.4\% to $15.0 \%)$. Considerably more edentulous seniors (>20\%) are to be found in Australia and Canada. The rates peak in the Netherlands and Finland $(27.6 \%$ and $36.0 \%$ respectively).

In summary, we may expect a further reduction in the caries prevalence among adults and - especially in the Netherlands - a decrease in tooth loss in adult age groups as well as - also in Finland - a decrease in total tooth loss at senior age. This process will continue as long as 'very low' or 'low' levels of caries prevalence in middle-aged adults and of total tooth loss in seniors are achieved [2].

To gain quantifiable results for measuring the efficiency of a dental care system, the level of oral health status (DHI) is linked with the macroeconomic resource consumption (DCCI), whereby Germany is taken as the index baseline $(\mathrm{DE}=100)$ (Table 3$)$.

If we look at the benefits and costs simultaneously, Sweden, Denmark and the United Kingdom possess the most efficient oral health care systems. Germany shows almost as little efficiency as Finland, which brings up the rear.

When considering the costs of the dental sector exclusively, all of the countries need far less resources than Germany. Even Sweden, whose inhabitants reveal a significantly higher level of oral health, spends onefifth less on dental care than Germany; and Switzerland - a country with a substantially higher income - and a correspondingly higher level of expectation, needs $20 \%$ fewer resources. In the efficiency chart (Figure 3) Sweden's outstanding position with regard to oral health status, Denmark's and the United Kingdom's in respect of cost-effectiveness and system-efficiency, Germany's with regard to its extreme resourceintensity and both Finland's and the Netherlands' stand out, owing to their low oral health levels. What is also easily recognizable is the fact that the majority of the countries spend about $0.5 \%$ to $0.7 \%$ of GDP on financing their oral care systems.

\section{Discussion}

The results of this study differ from the findings of the earlier study that had the same objective and covered the same participating countries [12]. This is because, in the meantime, it has been possible to include new available survey data $[16,21,23]$ and an extended DHI for measuring the population's oral health status was chosen. The application of this process resulted in important variations for several countries. Germany, for example, now ranks third in oral health status and the United Kingdom comes in fifth whereas, in the earlier study, they only reached the eighth and tenth position. Consequently, the efficiency of the dental sector in both countries improved from the last to the second to last rank and from sixth to third rank respectively. 


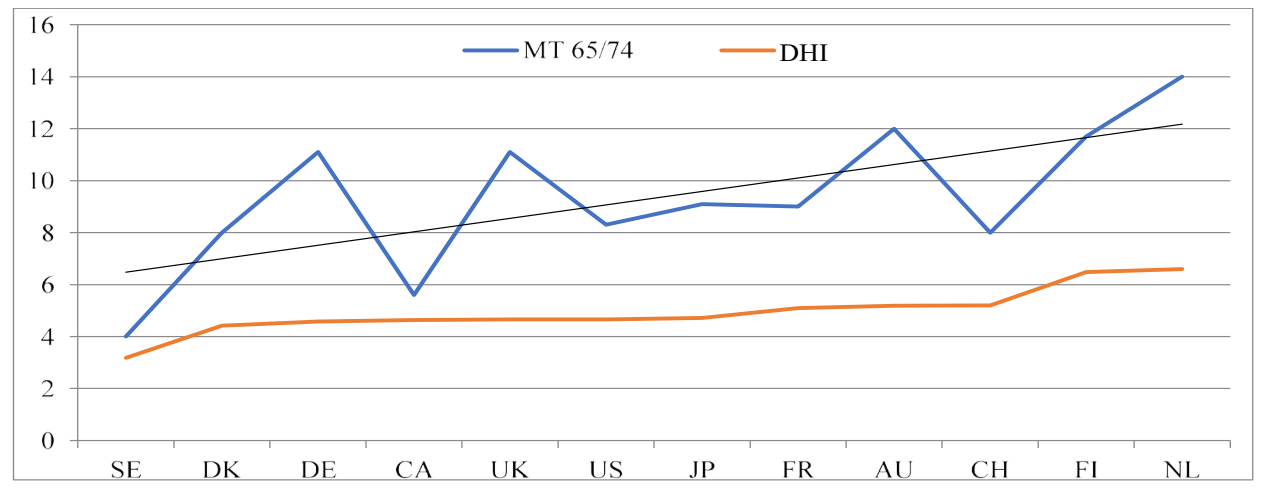

Figure 1. Comparison of MT among seniors (65/74) and DHI for the period 2006-2014

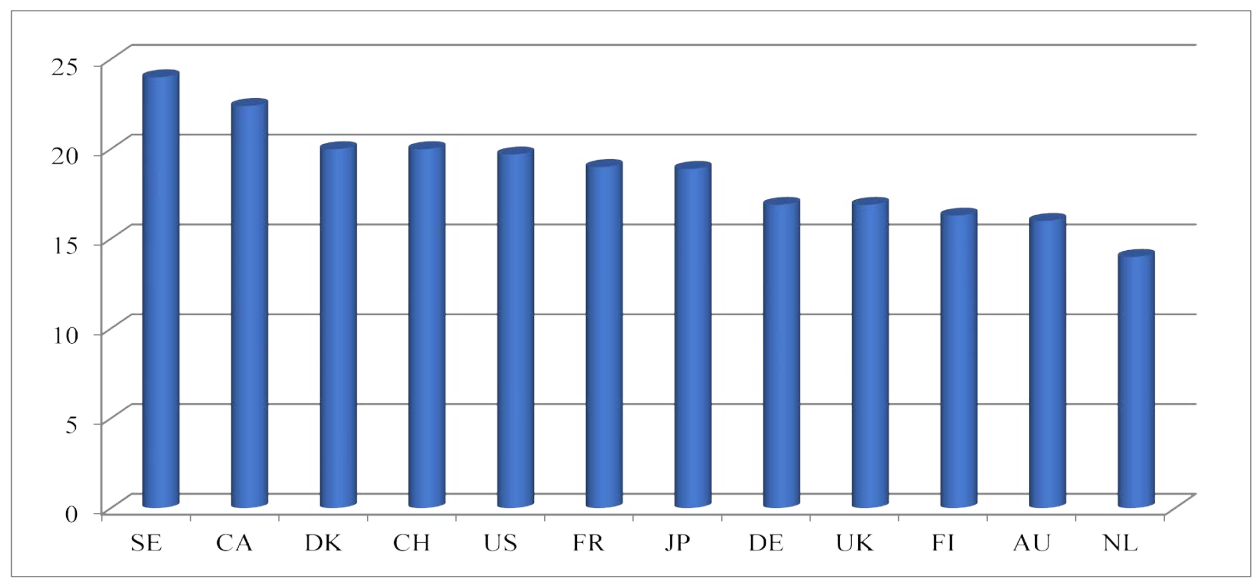

Figure 2. Amount of retained teeth in seniors (65/74) in selected highly developed countries 2006-2014 ${ }^{1}$ Calculated from MT values in Table 1

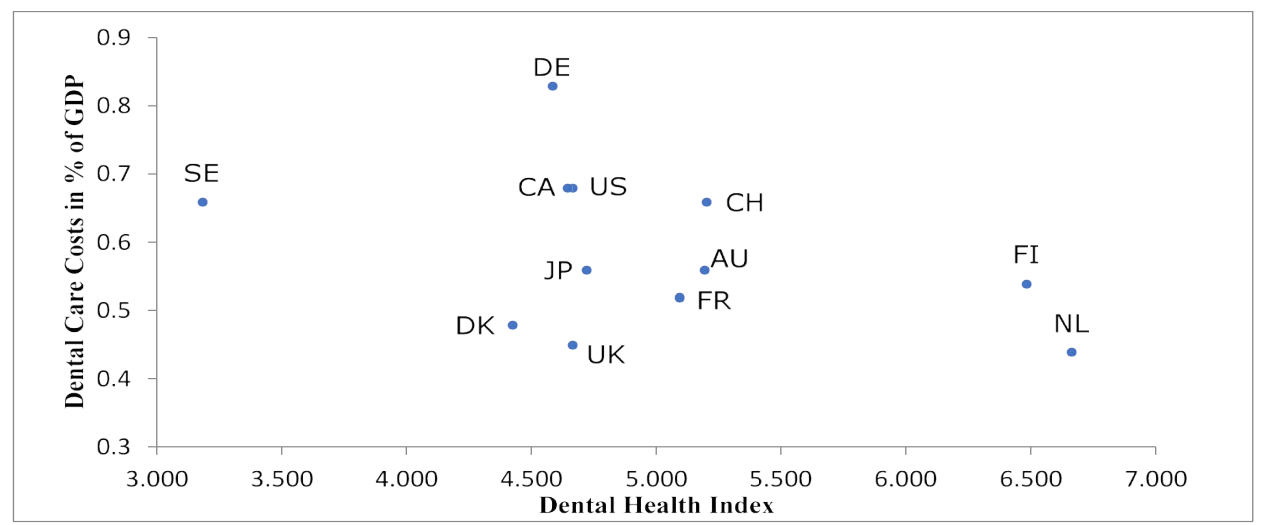

Figure 3. Efficiency matrix of the dental sector in selected highly developed countries 2012

\section{Possible reasons for variations in system performance}

Independently of the type of the oral health care system, its supply structures (public, private or mixed) and its terms of financing, good oral health can be achieved in any system, as can be seen in Table 1. Consequently, different oral care systems cannot explain variations in the effectiveness of dental care sectors. This is not surprising as, in spite of relevant divergences in the general health care types, it may not be overlooked that, in all of the different types of health care systems, dental care is regulated and financed differently from medical care. This is due to the higher demand elasticity on the part of patients and the lower intrinsic risk for oral diseases. While, in the medical sector, only a low proportion of private financing is required, the dental sector requires significantly higher private payments in order to avoid moral hazard (see Figure 4).

In respect of system-efficiency (EI), countries with a national health system occupy the first three places indicating that, in this regard, the type of oral health care system matters. The reason for this might be that, in these countries, oral health policy is more active and goaloriented when it comes to outcomes and cost-awareness.

In most countries, patients have to pay high co-payments for each treatment [31]. With the exception of Germany and France, where copayments for tooth preserving procedures are non-existent or very low, 
the provision of prosthetics has largely been removed from universal insurance coverage. Additionally, some countries offering universal health coverage have switched their dental treatment coverage from a benefit-in-kind coverage to a predetermined reimbursement amount for standardised benefits. This happened, for example, in Germany, the United Kingdom and Sweden [12]. On the whole, it can be asserted that, even if all treatments have to be financed privately, it is possible for the entire population to enjoy a good dental health status, as can be observed in Canada and Switzerland.

However, when looking at patient satisfaction with access to care, affordability, a safety net for low income earners and quality of care, the way in which a dental care system is designed does matter, once again. In this respect, especially US-American and Australian patients express a level of discontent with their health system that is several times higher than that of patients from European insurance-based sytems [5,34,35].

A relevant degree of influence on the level of oral health status is exerted by the patient's oral health behaviour and attitude. 'Regular dental attendance' is chosen as the key indicator for this area because many studies show a strong relationship between the regular use of dental services and improved dental health [23,26,36-38]. Studies with divergent results concerning the relationship between regular checkups and oral health status are hardly reliable because, in most instances, DMFT/DMFS values for oral health outcome were used and only small numbers of teenagers were studied for short periods [39-41]. In order to test whether there is a correlation between dental attendance and oral health benefits, more rigorous indicators such as 'MT' and/or 'edentulism' should be chosen and sufficient numbers of adult patients should be observed over a long period. The DMFT/DMFS value is not an appropriate measurement for such studies.

When using 'regular dental visits' as an indicator, findings show that regular dental attendance in adulthood is well established in Sweden and applies to $85 \%$ of the population. The majority (70\% to $80 \%)$ are enrolled in a recall system, on the clinician's initiative [42]. In Denmark, dental attendance rates rose steadily to over $88 \%$ among the 35-to 75+ age group [27]. The increased use of regular dental visits from $74 \%$ (2005) to $81 \%$ (2014) of 35 -to 74 year old Germans and the improvement in oral hygiene among seniors [23] might be responsible for raising the oral health status of adults in Germany over the last decade. Furthermore, during the same period, German dentists strengthened their preventive and tooth preserving activities [43]. Significantly lower are the rates of dental attendance in Canada, the USA, the United Kingdom, Australia and Japan (68\%, 65\%, 61\%, $45 \%$ and $40 \%$ respectively). If these countries nevertheless achieve a good level of oral health, this - in the case of the USA, Australia, and Canada - might be due to the widespread use of water fluoridation (75\%, 67\%, and $43 \%$ respectively) [44-46]. Table 4 shows Germany's

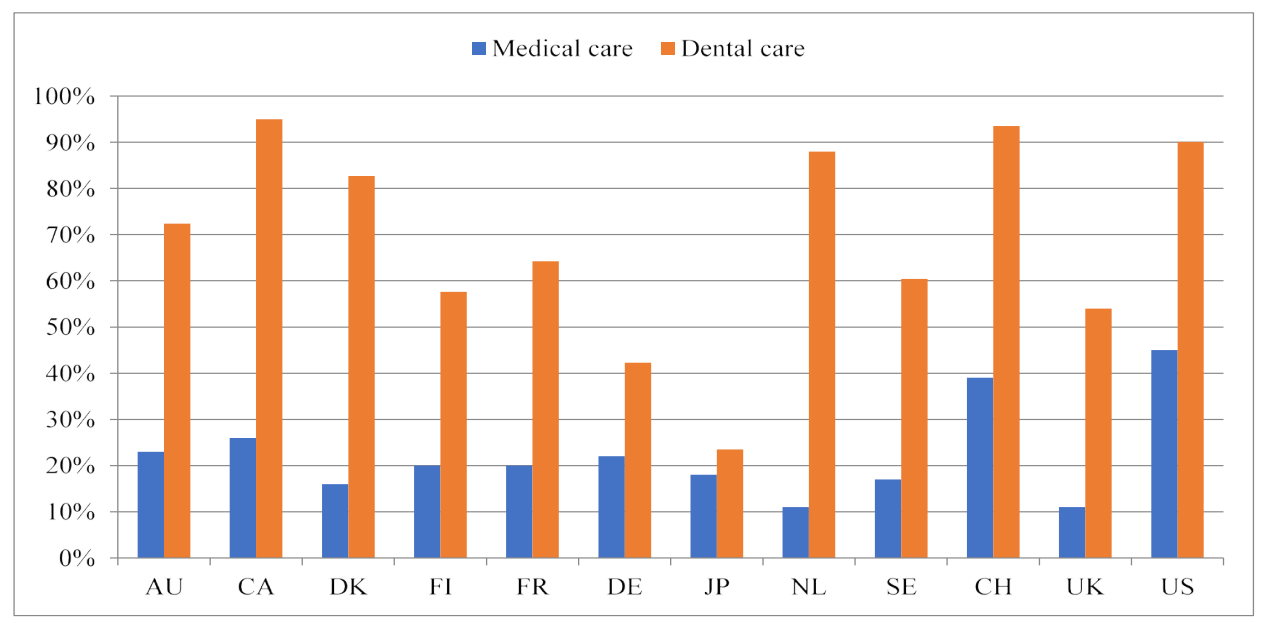

Figure 4. Total private payments (out-of-pocket-, private insurance payments) for medical and dental care in (\%) in selected highly developed countries 2010 [30,32,33]

Table 3. Efficiency index of the dental care sector in selected highly developed countries 2012

\begin{tabular}{|c|c|c|c|c|c|c|}
\hline \multirow[b]{2}{*}{ Country } & \multicolumn{2}{|c|}{ Dental Health Index (DHI) } & \multicolumn{2}{|c|}{ Dental Care Cost Index (DCCI) } & \multirow[b]{2}{*}{$\begin{array}{c}\text { Efficiency index }{ }^{2} \\
\text { (3) }\end{array}$} & \multirow[b]{2}{*}{ Rank } \\
\hline & $\begin{array}{l}\text { Value } \\
\text { (abs.) }\end{array}$ & $\begin{array}{c}\text { Index } \\
\text { (1) }\end{array}$ & $\begin{array}{l}\text { Total oral health care } \\
\text { costs in } \% \text { of GDP }\end{array}$ & $\begin{array}{c}\text { Index } \\
(2)\end{array}$ & & \\
\hline SE & 3.18 & 70 & 0.66 & 80 & 150 & 1 \\
\hline DK & 4.42 & 98 & 0.48 & 58 & 156 & 2 \\
\hline UK & 4.66 & 103 & 0.45 & 54 & 157 & 3 \\
\hline JP & 4.72 & 104 & 0.56 & 67 & 171 & 4 \\
\hline FR & 5.09 & 112 & 0.52 & 63 & 175 & 5 \\
\hline $\mathrm{AU}$ & 5.19 & 115 & 0.56 & 67 & 182 & 6 \\
\hline $\mathrm{CA}$ & 4.64 & 102 & 0.68 & 82 & 184 & 7 \\
\hline US & 4.66 & 103 & 0.68 & 82 & 185 & 8 \\
\hline $\mathrm{CH}$ & 5.20 & 115 & 0.66 & 80 & 195 & 9 \\
\hline NL & 6.60 & 146 & 0.44 & 53 & 199 & 10 \\
\hline $\mathrm{DE}$ & 4.53 & 100 & 0.83 & 100 & 200 & 11 \\
\hline FI & 6.48 & 143 & 0.54 & 65 & 208 & 12 \\
\hline
\end{tabular}

1) Data from 2012 2) (3) $=(1)+(2)$ 
room for improvement in oral health behaviour - in comparison with the country that enjoys the best oral health status, which is Sweden.

Particularly the approximal cleaning, the snacking and the smoking habits of German adults need to be improved, whereby the high smoking rates combined with low approximal self-care might be responsible for the comparatively poor periodontal status of the adult German population $[18,23,47]$.

In the cluster that comprises a predominantly preventive and tooth-preserving approach, the existence of a goal-setting and goalmonitoring oral health policy, combined with the availability of accompanying scientific dental services research, it is possible to observe another factor that influences the performance of dental care systems. All of these conditions are present in Sweden, Denmark, the United Kingdom, the USA, Japan and Australia. Particularly in Japan, this combination of factors seems to explain why, in spite of low rates of regular dental visits, the population's oral health level, at a DHI of 4.72, is relatively high $[18,50,51]$. In the case of Germany, these framework conditions are widely lacking.

Despite a strong decline in caries prevalence in Sweden and Germany, great differences exist with respect to treatment philosophies as can be seen from the provision of crowns and endodontic measures. While these treatment measures have been on the decrease for a long time in Sweden, the provision with crowns continues to rise and the endodontic treatments per patient remain constant in Germany $[18,23,52]$. In contrast to Denmark, which introduced preventive benefits for adults into its social benefits catalogue [36], no such step has been taken thus far in Germany, since the self-administration bodies of the dentists and sickness funds have so far failed to reach an agreement on the corresponding benefits.
The level of expenditure on dental care depends, inter alia, on the form and size of out-of-pocket payments, as well as on the average per capita income of the population [53,54]. The most influence is exerted on the results by the out-of-pocket proportion, which is most pronounced in Switzerland and is lowest in the Netherlands, Japan, Germany and France (Figure 5).

However, in countries where dental care for adults has largely been privatised, patients often feel compelled to take out private insurance, which attenuates the effect of a patient's co-payment. This pattern is widespread in the Netherlands, the USA, France and Canada. Therefore, out-of-pocket and private insurance contributions must be considered together, to be able to capture the real effect of private expenditure on a dental sector's level of cost. If this is done, the total private payments turn out to be highest in Canada, Switzerland, the USA, the Netherlands and Denmark and lowest in Japan and Germany (Figure 5). In line with the principles of health economy theory, one should expect the macroeconomic costs for dental care to be relatively low in Canada, Switzerland, the USA, the Netherlands and Denmark. In fact, this is true for the Netherlands and Denmark and - to a lesser degree (because of substantially higher levels of income per capita) also for Switzerland and the US as we can see from Table 3, column 4. On the other hand, in both countries with the lowest share of private payments, Japan and Germany, one would expect the macroeconomic consumption of resources to be the most elevated. The figures confirm this for Germany, but not for Japan (Table 3). It is quite possible that, in Japan, other factors effectively limit the trend towards rising dental care costs. Such factors could include Japan's below average income level, as well as the strict tooth-preserving treatment approaches that are favoured by oral health policy and practised by Japanese dentists. Similar causes might explain why the United Kingdom manages its

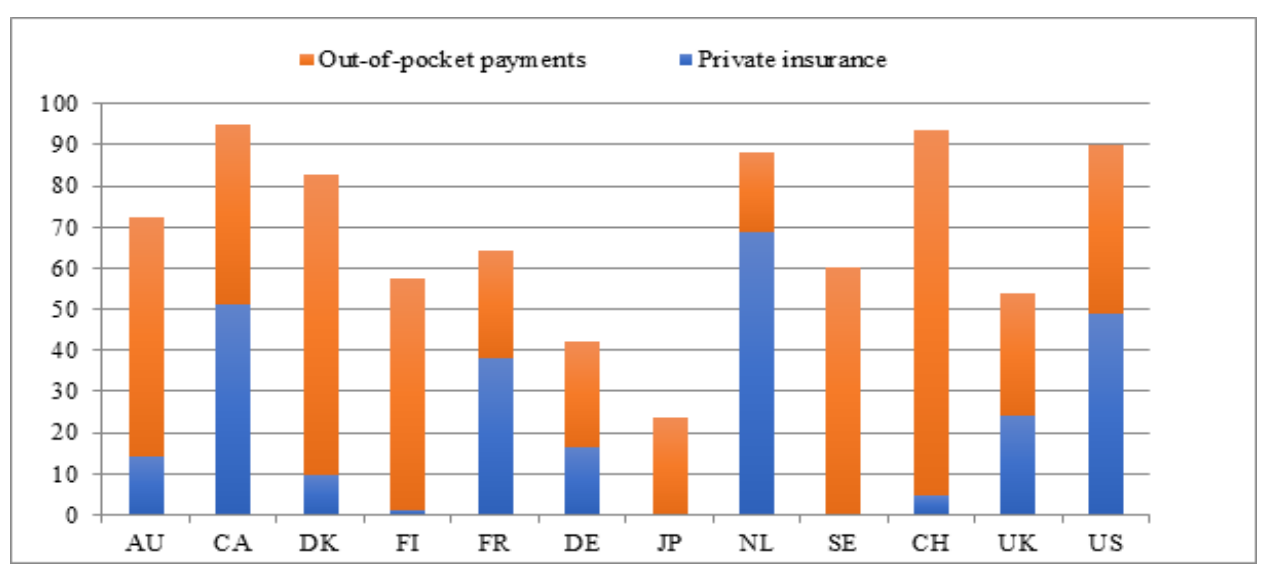

Figure 5. Distribution of private payments (out-of-pocket and private insurance) for dental care (\%) in a selection of highly developed countries 2010

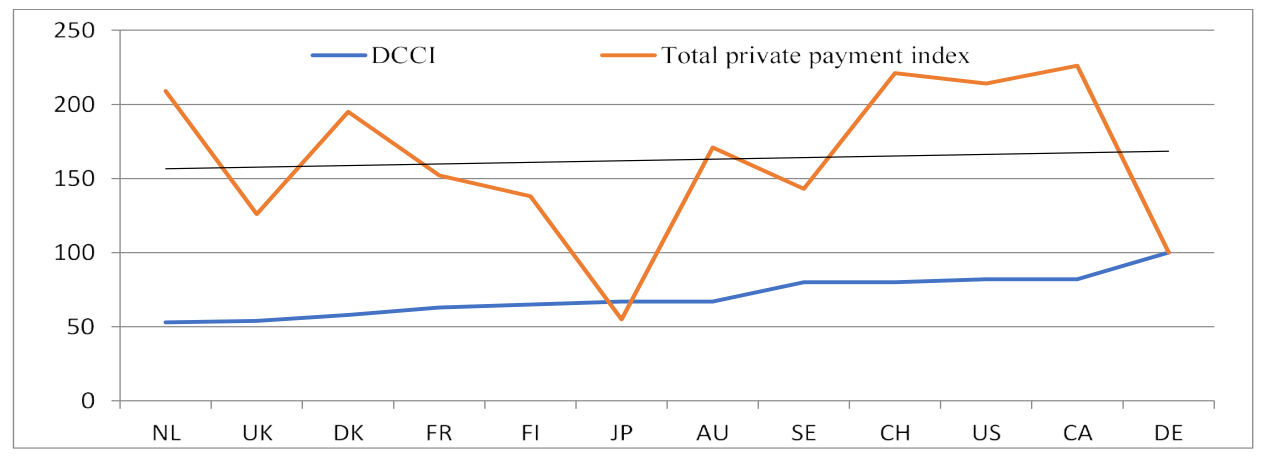

Figure 6. Comparison of total private payment index and dental care cost index 
Table 4: Oral health behaviour in Swedish and German adults (35-74 yrs) 2013/14

\begin{tabular}{|c|c|c|c|c|c|c|}
\hline \multirow[b]{2}{*}{ Country } & \multicolumn{6}{|c|}{ Oral health behaviour } \\
\hline & $\begin{array}{l}\text { Regular dental visits } \\
\text { (in \%) }\end{array}$ & $\begin{array}{l}\text { Daily tooth brushing } \\
\geq \text { twice } \\
\text { (in \%) }\end{array}$ & $\begin{array}{c}\text { Regular use of tooth } \\
\text { picks } \\
\text { (in \%) }\end{array}$ & $\begin{array}{c}\text { Sugar intake/capita p.a. } \\
\text { (in kg) }\end{array}$ & $\begin{array}{c}\text { Snacks between meals } \\
(1-2 \text { times }) \\
\text { (in \%) }\end{array}$ & $\begin{array}{l}\text { Smokers }^{1} \\
\text { (in \%) }\end{array}$ \\
\hline SE & 85 & 85 & 33 & 36.5 & 23 & 23 \\
\hline DE & 81 & 80.5 & 11.5 & 36.9 & 54.6 & 32 \\
\hline
\end{tabular}

1) Average of women and men

dental care system so effectively, cost-consciously and efficiently, with just half of the resources expended by Germany. This assessment also holds true, if it is assumed that the National Health Service (NHS) is underfinanced, as was recently again determined by a parliamentary commission [56].

Thus, the assumption that sensible co-payments for adults reduce overall dental expenditure and limit a dental system's costs is confirmed by our study as well. Figure 6 provides a graphical demonstration. What is striking is the paralell between the trend curve of the country's total private payment index values and the DCCI values, indicating a relationship between both indices.

Germany had proven this assumption to be valid, already in the decade 1980 to 1990, when the country first introduced a $20 \%$ copayment for prosthetic treatments (1978), which was later doubled (1989), leading to a decrease in total dental care costs, in terms of \% of GDP, from $1.16 \%$ (1980) to $0.84 \%$ (1990) [10] which have remained stable at this level. The relatively low co-payment level currently in place in Germany seems to be responsible - in combination with the known inefficiencies in the German system $[10,57,58]$ - for the still extraordinarily high macroeconomic resource consumption by the dental care sector. The mere fact that Germany has a particularly dense social security net (no co-payments for the needy, ceilings on out-ofpocket payments for patients and families) which results in practically no barriers to access, cannot explain the excessive levels of expenditure. In this regard, a great deal of anecdotal evidence exists to suggest that Germany has great potential for increasing the efficiency of its dental care sector.

\section{Conclusion}

This international comparison using the new instruments of analysis opens up new horizons for optimising dental care systems. The findings show that good dental status on a population basis can be achieved in any health system, irrespective of the structures used in funding dental care. However, when it comes to patient satisfaction, the manner in which an oral health system is designed matters. Seen from this perspective, the European insurance-based systems perform better. The type of system also matters, when it comes to efficiency considerations. Here, national health systems seem to perform better.

Across systems, the comparison shows that systems that foster preventive and tooth-preserving strategies, also for adults, progress faster and perform better in terms of effectiveness and efficiency. In highly developed countries, depending on a country's income level, a macroeconomic cost level of between $0.5 \%$ and $0.7 \%$ can be regarded as a benchmark for an efficient dental care system. While Germany meanwhile ranks third in oral health status (system-effectiveness) among the countries under study, its performance in terms of systemefficiency remains rather substandard.

\section{References}

1. Holm-Pedersen P, Vigild M, Nitschke I, Berkey DB (2005) Dental care for aging populations in Denmark, Sweden, Norway, United Kingdom, and Germany. J Dent Educ 69: 987-997. [Crossref]
2. Marthaler TM (2004) Changes in dental caries 1953-2003. Caries Res 38: 173-181. [crossref]

3. Nithila A, Bourgois D, Barmes DE, Murtomaa H (1998) WHO Global Oral Data Bank, 1986-96: an overview of oral health surveys at 12 years of age. Bull World Health Organ 76: 237-244. [crossref]

4. Palmqvist S, Söderfeldt B, Vigild M, Kihl J (2000) Dental conditions in middle-aged and older people in Denmark and Sweden: a comparative study of the influence of socioeconomic and attitudinal factors. Acta Odontol Scand 58: 113-118. [crossref]

5. Schoen C, Osborn R, Squires D, Doty MM, Pierson R, Applebaum S (2010) How health insurance design affects access to care and costs, by income, in eleven countries. Health Aff (Millwood) 29: 2323-2334. [crossref]

6. Petersen PE (2003) The World Oral Health Report 2003: continuous improvement of oral health in the 21st century - the approach of the WHO Global Oral Health Programme. Community Dent Oral Epidemiol 31: 3-23. [crossref]

7. Karlsbeek H, Truin GJ, Burgersdijk R, van `t Hof M (1991) Tooth loss and dental caries in Dutch adults. Community Dent Oral Epidemiol 19: 201-204. [crossref]

8. Crocombe LA, Mejia GC, Koster CR, Slade GD (2009) Comparison of adult oral health in Australia, the USA, Germany and the UK. Aust Dent J 54: 147-153. [crossref]

9. Bauer J, Neumann Th, Saekel R (1995) Oral health and dental provision in the Federal Republic of Germany 1994. Successes, deficits and prospects. Berlin, Schmidt Verlag, (in German).

10. Bauer J, Neumann TH, Saekel R (2009) Dental care provision in Germany. Oral health status and quality of dental care - a critical review. Bern, Verlag Hans Huber, (in German).

11. Saekel R (2016) Comparison of oral health status in Asia: Results for eight emerging and five high income countries or regions and implications. Chin J Dent Res 19: 191206. [crossref]

12. Saekel R (2016) New analytical tools for evaluating dental care systems - Results for Germany and selected highly developed countries. CJDR 19: 77-88.

13. Murray CJ, LopezAD (1996) The Global Burden of Desease. World Health Organization, World Bank, Harvard School of Public Health. Cambridge, Massachusetts. Boston, Harvard University Press.

14. Quiñonez C (2013) Why was dental care excluded from Canadian Medicare? Network for Canadian Oral Health Research (NCOHR). NCOHR Working Paper Series, 1:1. Available at: http://ncohr-rcrsb.ca/knowledge-sharing/working-paper-series/content/ quinonez.pdf Accessed: December 6, 2016.

15. Haikola B (2014) Oral health among finns aged 60 years and over. Edentoulesness, fixed protheses, dental infections detected from radiograph and their associating factors. Acta Univ Oul D Medica 1264, Dissertation, Juvenis Print, Tampere, 2014. Available at: www.jultika.oulu.fi/files/isbn9789526206141.pdf. Accessed: February 26, 2017.

16. Basner R, Santamaria RM, Schmoeckel J, Schüler E, Splieth CH (2017) Complementary epidemiological study on group prophylaxis 2016 Bonn, DAJ (in German).

17. World Health Organisation (2017) Global Oral Data Bank. Available at: http://www mah.se/CAPP/. Accessed: February 26, 2017.

18. Norderyd O, Koch G, Papias A (2015) Oral health of individuals aged 3-80 years in Jönköping, Sweden during 40 years (1973-2013). I. Review of findings on oral care habits and knowledge of oral health. II. Review of clinical and radiographic findings. Swed Dent J 39: 57-86.

19. Ministry of Health and Welfare (2011) Survey of dental diseases. Ministry of Health and Welfare, 2012. Available at: http://www.mhlw.go.jp/toukei/list/dl/62-17c23-1.pdf. Accessed: February 26, 2017.

20. Suominen-Taipale L, Nordblad A, Vehkalathi M, Aromaa A (eds.) (2008) Oral Health in the Finnish Adult Population. Health 2000 Survey. National Public Health Institute, Finland, Helsinki. Available at: https://www.julkari.fi/bitstream/ handle/10024/103030/2008b25.pdf?sequence=1. Accessed: February 26, 2017. 
21. Stock C, Jürges H, Shen J, Bozorgmehr K, Listl S (2016) A comparison of tooth retention and replacement across 15 countries in the over-50s. Community Dent Oral Epidemiol 44: 223-231. [crossref]

22. Health Canada. Report on the findings of the Oral Health Module of the Canadian Health Measures Survey 2007-2009, 2010. Available at: http://www.dal.ca/content/ dam/dalhousie/pdf/dentistry/ICOH2010/930\%20Harry\%20Ames.pdf.Accessed: February 26, 2017

23. Jordan R, Micheelis W (Eds.). Fifth German Oral Health Study - DMS V. Cologne, Deutscher Zahnärzte Verlag, 2016 (in German).

24. Dye BA, Li X, Thornton-Evans G (2012) Oral health disparities as determined by selected healthy people 2020 oral health objectives for the United States 2009-2010. NCHS Data Brief 104: 1.8.

25. Fuller E, Steele J, WattR, Nuttall N. Oral health and function - a report from the Adullt Dental Health Survey 2009. The Health and Social Care Information Centre. March 24th, 2011. Available at: http://content.digital.nhs.uk/catalogue/PUB01086/adul-dentheal-surv-summ-them-the1-2009-rep3.pdf. Accessed: July 10, 2017.

26. Steele J, O'Sullivan I. Executive Summary: Adult Dental Health Survey 2009. The Health and Social Care Information Centre. March 24th 2011. Available at: http:/ content.digital.nhs.uk/catalogue/PUB01086/adul-dent-heal-surv-summ-them-exec2009-rep2.pdf. Accessed: July 10, 2017.

27. Li KY, Wong MC, Lam KF, Schwarz E (2011) Age, period, and cohort analysis of regular dental care behavior and edentulism: a marginal approach. BMC Oral Health 11: 9. [crossref]

28. White D, Pitts N, Steele J, Sadler K, Chadwick B (2009) Disease and related disorders a report from the Adult Dental Health Survey. The Health and Social Care Information Centre, March 24th 2011. Available at: http://content.digital.nhs.uk/catalogue/ PUB01086/adul-dent-heal-surv-summ-them-the2-2009-rep4.pdf. Accessed: July 10, 2017.

29. Zitzmann NU, Staehelin K, Walls AW, Menghini G, Weiger R, et al. (2008) Changes in oral health over a 10-year period in Switzerland. Eur J Oral Sci 116: 52-59. [Crossref]

30. Organisation for Economic Cooperation and Development: OECD Health Statistics 2014. Available at: www.oecd.org/els/health-systems/health-data.htm. Accessed: February 26, 2017.

31. Klingenberger D, Schneider M, Hofmann U, Köse A (2015) Comparison of Dental Fees in Europe. Cologne, Deutscher Zahnärzte Verlag.

32. Boyle S (2011) United Kingdom (England): Health system review. Health Syst Transit 13: 1-483, xix-xx. [crossref]

33. Office of Fair Trading. Dentistry. An OFT market study, May, 2012. Available at: http:// webarchive.nationalarchives.gov.uk/20140402142426/http:/www.oft.gov.uk/shared oft/market-studies/Dentistry/OFT1414.pdf. Accessed: December 6, 2016.

34. Papanicolas I, Cylus J, Smith PC (2013) An analysis of survey data from eleven countries finds that 'satisfaction' with health system performance means many things. Health Aff (Millwood) 32: 734-742.

35. Grignon M, Hurley J, Wang I, Allin S (2008) Inequity in a market-based health system: Evidence from Canada's dental sector. CHEPA Working Paper Series; Paper 0805. Centre for Health Economics and Policy Analysis, McMaster University. Available at: http://citeseerx.ist.psu.edu/viewdoc/download;jsessionid=E5892D10AF8AC0DFDD 4E72D397EF52A0?doi=10.1.1.686.4307\&rep=rep1\&type=pdf. Accessed: December $6,2016$.

36. Petersen PE, Kjøller M, Christensen LB, Krustrup U (2004) Changing dentate status of adults, use of dental health services, and achievement of national dental health goals in Denmark by the year 2000. J Public Health Dent 64: 127-135. [Crossref]

37. Ellershaw AC, Spencer AJ (2011) Dental attendance patterns and oral health status. Dental statistics and research series no. 57, Cat no. DEN 208. Canberra, AIHW. Available at: http://www.aihw.gov.au/WorkArea/DownloadAsset.aspx?id=107374186 74\&libID=10737418673. Accessed: July 4, 2017.

38. Todd JE, Lader D (1991) Adult dental health in the United Kingdom. Her Majesty's Stationary Office.
39. Kentomaki T, Luoma AR (1993) Dental caries and use of resources in relation to individual inspection interval in systematic oral health care. Vantaa National Research Centre of Welfare and Health. Helsinki.

40. Morrant AM, Holloway PJ, Taylor GO (1995) A novel school dental screening programme. Community Dent Health 12: 128-132.

41. Wang N, Marstrander P, Holst D. Övrum L, Dahle T (1992) Extending recall intervalseffect on resource consumption and dental health. Community Dent Oral Epidemiol 20: 122-124. [Crossref]

42. Hugoson A, Koch G, Göthberg C, Helkimo AN, Lundin SA, et al. (2005) Oral health of individuals aged 3-80 years in Jönköping, Sweden during 30 years (1973-2003). I: Review of findings on dental care habits and knowledge of oral health. Swed Dent $J$ 29:125-138. [Crossref]

43. Hussein RJ, Walter U, Schneller TH (2014) Attitudes of dentists with regard to prevention. German Dental Journal 69: 90-96.

44. Slade GD, Sanders AE, Do C, Roberts-Thomson K, Spencer AJ (2013) Effects of fluoridated drinking water in dental caries in Australian adults. J Dent Res 92: 376-382. [Crossref]

45. Government of Canada. Guidelines for Canadian Drinking Water Quality: Guideline Technical Document - Fluoride, 2011. Available at: http://www.cdc.gov/fluoridation/ statistics/2012stats.htm. Accessed: July 10, 2017.

46. Centers for Disease Control and Prevention. Community water fluoridation 2012 Available at: http://www.cdc.gov/fluoridation/statistics/2012stats.htm. Accessed: July $10,2017$.

47. Edman K, Öhrn K, Nordström R, Holmlund A, Hellberg D (2015) Trends over 30 years in the prevalence and severity of alveolar bone loss and the influence of smoking and socio-economic factors - based on epidemiological surveys in Sweden 1983-2013. In J Dent Hygiene 13: 283-291. [Crossref]

48. World Bank (2016) Smoking prevalence, males and females (\% of adults). Available at: http://data.worldbank.org/indicator/SH.PRV.SMOK.MA. Accessed: July 10, 2017.

49. Malmö University. Sugar Consumption Euro 2012. Available at: http://www.mah.se/ CAPP/Globalsugar/Risk-Factors/Sugar-Global-Data/Global-Sugar-Consumption/ Sugar-Consumption-EURO/. Accessed: July 10, 2017.

50. Tamaki Y, Nomura Y, Teraoka K, Nishikahara F, Motegi M, et al. (2004) Characteristics and willingness of patients to pay for regular dental check-ups in Japan. J Oral Sci 46 : 127-133. [crossref]

51. Japanese Society for Oral Health (JSOH) What's JSOH? Available at: http://kokuhoken or.jp/jsdh/en.html. Accessed: July 10, 2017.

52. Kassenzahnärztliche Bundesvereinigung. Yearbook 2015. Available at: http://www. kzbv.de/kzbv-jahrbuch-2015.media.b58d83c8c7fb6f73b35563fab351cb72.pdf. Accessed: July 10, 2017.

53. Liu S, Chollet D (2006) Price and Income Elasticity of the Demand for Health Insurance and Health Care Services. A Critical Review of the Literature: Final Report, March 24th, Mathematica, Policy Research, Inc. Available at: http://www.mathematica-mpr. com/-/media/publications/PDFs/priceincome.pdf. Accessed: July 10, 2017.

54. Sintonen H, Linnosmaa I (2000) Economics of dental services. In: Culyer AJ, Newhouse JP (eds). Handbook of health economics, ed 1. Amsterdam; Elsevier Science: $1251-1296$.

55. Akimoto H (2009) Future of Dentistry. 2009. Available at: http://www.academia edu/4566667/AKIMOTO_Hidetoshi_Future_of_Dentistry. Accessed: July 10, 2017.

56. House of Lords. The Long-term Sustainability of the NHS and Adult Social Care Report of Session 2016-2017 HL Paper 151, 5 April 2017. Available at: https://www. publications.parliament.uk/pa/ld201617/ldselect/ldnhssus/151/151.pdf. Accessed: July $10,2017$.

57. Expert Advisory Board for the Concerted Action in Health Care. Report 2000/2001. Demand-Orientation and Efficiency. Vol. III: Over-, Under-, and Malpractice. III, 4: Dental, Oral and Orthodontic Maladies. Baden-Baden, Nomos Verlag, 2002 (in German).

58. Madsen H (2016) Orthodontics - aggressive marketing and inefficient treatment. Zahnärztlicher Gesundheitsdienst 46: 8-10 (in German).

Copyright: $\odot 2018$ Saekel R. This is an open-access article distributed under the terms of the Creative Commons Attribution License, which permits unrestricted use, distribution, and reproduction in any medium, provided the original author and source are credited. 